\title{
Prevalence and Risk Factors Associated With Preeclampsia, Low Birth Weight and Postpartum Hemorrhage in Northern Ghana
}

Benjamin Ahenkorah ( $\nabla$ benahenkorah.cos@gmail.com )

Kwame Nkrumah University of Science and Technology

\section{Samuel Sakyi}

Kwame Nkrumah University of Science and Technology

\section{Gideon Helegbe}

University for Development Studies

\section{Eddie Owiredu}

Kwame Nkrumah University of Science and Technology

\section{Winfred Ofosu}

Ghana Health Service

\section{Edmund Der}

University for Development Studies

\section{Richard Ephraim}

University of Cape Coast

\section{Benjamin Amoani}

University of Cape Coast

\section{Priscilla Arthur}

University of Cape Coast

\section{Dominic Apio}

Ghana Health Service

\section{Susanna Cheetham}

Kwame Nkrumah University of Science and Technology

\section{Ben Gyan}

Noguchi Memorial Institute for Medical Research

\section{Research Article}

Keywords: PPH, PE, LBW, Hb-genotype, Sickling, Blood group, G6PD, ANC, Residency

Posted Date: November 24th, 2020

DOl: https://doi.org/10.21203/rs.3.rs-109200/v1 
License: (c) (i) This work is licensed under a Creative Commons Attribution 4.0 International License. Read Full License 


\section{Prevalence and risk factors associated with preeclampsia, low}

\section{2 birth weight and postpartum hemorrhage in Northern Ghana.}

3 Benjamin Ahenkorah ${ }^{1,2^{*}}$, Samuel Asamoah Sakyi ${ }^{1}$, Gideon Helegbe ${ }^{4}$, Eddie-Williams Owiredu ${ }^{1}$,

4 Winfred Ofosu 5 , Edmund Muonir Der ${ }^{4}$, Richard K.O. Ephraim ${ }^{3}$, Benjamin Amoani ${ }^{3}$, Priscilla

5 Arthur-Johnson ${ }^{7}$, Dominic Apio ${ }^{5}$, Susanna Cheetham ${ }^{8}$, Ben Gyan ${ }^{6}$

$6{ }^{1}$ Department of Molecular Medicine, School of Medicine and Dentistry, Kwame Nkrumah

7 University of Science and Technology, Kumasi, Ghana

$8 \quad{ }^{2}$ Department of Medical Laboratory Science, Bolgatanga Technical University, Bolgatanga-Upper

9 East Region, Ghana

${ }^{3}$ Department of Biomedical Sciences, University of Cape Coast, Cape Coast, Ghana

${ }^{4}$ School of Medicine and Health Science, University for Development Studies, Tamale, Ghana

12

${ }^{5}$ Ghana Health Service, Upper East Region, Ghana

${ }^{6}$ Department of Immunology, Noguchi Memorial Institute for Medical Research

${ }^{7}$ School of Medical Sciences, University of Cape Coast, Cape Coast, Ghana

${ }^{8}$ School of Public Health, Kwame Nkrumah University of Science and Technology, Kumasi, Ghana

*Corresponding author

E-mail: benahenkorah.cos@gmail.com/bennahie@yahoo.com 


\section{Abstract}

21 Background: The study evaluated the risks for developing low birth weight (LBW), preeclampsia $(\mathrm{PE})$ and postpartum hemorrhage $(\mathrm{PPH})$ in relation to maternal socio-demographic, obstetric characteristics and clinical laboratory information obtained at $1^{\text {st }}$ antenatal care (ANC) visit.

Methods: The study included 268 pregnant women attending $1^{\text {st }}$ ANC visit at the Bolgatanga Regional Hospital. Structured questionnaires were used to obtain socio-demographic and obstetric data from respondents. The main variables were LBW, PPH, PE, mode of delivery, residency, gestational age at $1^{\text {st }}$ ANC visit, maternal age, sickling positivity, $\mathrm{Hb}$ at $1^{\text {st }}$ ANC visit, Hb genotype and G6PD status. Odds ratio [OR, 95\% confidence interval (CI)] for the association between sociodemographic, obstetric characteristics and clinical variables in relation to PE, LBW and PPH were assessed using logistic regression model.

Results: The prevalence of PE, LBW and PPH were 25.4\% (68/268), 15.7\% (42/268) and 6.0\% (16/268), respectively. For PE, delayed $1^{\text {st }}$ ANC visit (AOR=16.82, 95\% CI (3.61-78.5), p=0.000) and younger maternal age $(\mathrm{AOR}=15.19,95 \% \mathrm{CI}(1.85-124.56), \mathrm{p}=0.011)$ were independently associated with higher odds whereas vaginal delivery $(\mathrm{AOR}=0.32,95 \% \mathrm{CI}(0.15-0.71), \mathrm{p}=0.015)$ was independently associated with reduced odds. Delayed $1^{\text {st }}$ ANC visit (AOR=0.12, 95\% CI (0.030.47)), $\mathrm{p}=0.002$ ) independently reduced the risk of $\mathrm{PPH}$ whereas the male gender ( $\mathrm{AOR}=7.75,95 \%$ CI (1.60-37.51), $\mathrm{p}=0.011)$ independently increased the risk of PPH. Lastly, delayed $1^{\text {st }}$ ANC visit $(\mathrm{AOR}=3.26,95 \% \mathrm{CI}(1.05-10.10), \mathrm{p}=0.041)$ was independently associated with increased odds of LBW whereas vaginal delivery $(\mathrm{AOR}=0.36,95 \% \mathrm{CI}(0.17-0.74), \mathrm{p}=0.006)$ was an independent risk factor for LBW in the multivariate model.

Conclusion: The study identified delayed ANC visit as an independent risk factor for PE, LBW and PPH in Northern Ghana. Vaginal delivery and younger maternal age were also independent risk factors for PE. Additionally, the male gender was independently associated with PPH whereas vaginal delivery was independently associated with LBW. We recommend that public health education for pregnant women that highlights the importance of early ANC visit be enhanced. This will facilitate early identification and intervention for women with risk of foeto-maternal 
50

\section{Introduction \\ Introduction}

complications. Younger women should be educated on the dangers of early marriages with its attendant foeto-maternal complications.

Keywords: PPH; PE; LBW; Hb-genotype; Sickling; Blood group; G6PD; ANC; Residency

According to the World Health Organization (WHO), low birth weight (LBW) refers to the weight at birth that is less than $2500 \mathrm{~g}$ [1]. Birth weight is an essential predictor of infant growth and survival.

Infants born with low birth weight (LBW) begin life immediately disadvantaged and face extremely

58 poor survival rates [2, 3]. LBW infants suffer severe cognitive and neurological impairment,

59 increased risk of high blood pressure, obstructive lung disease, cholesterol, renal damage, acute

0 diarrhea, impaired immune function and poor cognitive development $[4,5]$. Globally, about $16 \%$ of

61 live births, or 20 million infants per year, are born with LBW, with $90 \%$ of these born in developing

62 countries [6]. The prevalence of LBW varies between and within geographical regions. In Northern

63 Ghana, the prevalence of LBW was $13.8 \%$ based on data collected between 2009 and 2011 [7].

64 Current data on LBW is thus needed. The factors associated with LBW is multifactorial, including

65 nutritional factors, younger and advanced maternal age, parity, limited birth spacing, low pre-

66 pregnancy BMI and parasitic infections $[8,9]$.

67 Postpartum hemorrhage (PPH) is blood loss of $\geq 1000 \mathrm{ml}$ in the immediate post-partum period [10].

68 Although there have been several advances aimed at its prevention and management in recent years,

69 PPH remains a leading cause of maternal mortality and morbidity globally, affecting approximately

$2 \%$ of all women who give birth [11]. In Ghana, the prevalence of PPH was 4.4\% in 2018 [12]. Like 
$71 \mathrm{LBW}$, the cause of $\mathrm{PPH}$ is multifactorial and has been related with late antenatal care (ANC)

72 registration [13], preexisting maternal anaemia [11], prolonged labor and younger maternal age [12].

73 Preeclampsia (PE) is the leading cause of maternal morbidity and mortality globally [14]. The 74 prevalence of PE is $2-8 \%$ worldwide and up to $10 \%$ in developing countries [15]. In Ghana, the 75 prevalence of PE ranged between 6.55 and 7.03\% from 2006-2009 [16]. Data from 2014 revealed 76 an increased prevalence of PE (48.8\%) and eclampsia (13.5\%) among women with hypertensive 77 disorders of pregnancy [17]. Current data on PE, particularly in Northern Ghana is wanting. The progression of PE to eclampsia is very alarming. Eclampsia is associated with several adverse fetal outcomes including preterm birth, small-for-gestational-age babies, placental abruption, and perinatal death. Although PE is a pregnancy-associated disorder with no definite cause, factors that 81 have been identified to be associated with PE include maternal age (below 18 years or advanced age), first pregnancy, personal and family history of PE, obesity and preexisting medical conditions, gestational diabetes and hypertension [18].

Taken together, LBW, PPH and PE remain public health threats and contribute to pregnancyassociated morbidity and mortality, particularly in developing countries. This notwithstanding, only few studies have been conducted to highlight potential risk factors of these conditions to facilitate prevention and management in Ghana, especially in the Northern parts of the country where healthcare facilities are very limited. This study aimed at evaluating the risk factors of LBW, PPH and PE in the Northern part of Ghana. 


\section{Methods}

\section{Study Design and population}

95 The study was conducted at the Bolgatanga Regional Hospital, a tertiary care center in the Upper 96 East Region of Ghana from March 2018 to March, 2019. A total of 268 consecutive consenting 97 pregnant women were included in the study. Participants included did not have eclampsia, deliveries with birth defects, had singleton gestation and delivered full term babies.

\section{Obstetric characteristics and perinatal outcomes}

Using a well-structured closed ended questionnaire according to WHO guidelines [19], sociodemographic and obstetric data including maternal age, gestational age at $1^{\text {st }}$ visit, parity, marital status, occupation and residency were obtained from each participant.

\section{Laboratory methods}

105 Five milliliters of venous blood was drawn from antecubital vein of each study participant for $\mathrm{ABO} / \mathrm{Rh}$ blood group test, sickling test, haemoglobin genotype, haemoglobin concentration estimation at $1^{\text {st }}$ visit and G6PD quantitative test. $\mathrm{ABO}$ and $\mathrm{Rh}$ blood grouping was done using commercially prepared monoclonal anti-A, anti-B, and anti-D [20]. Haemoglobin concentration was determined using the Sysmex KX-21 N Automated three-part differential Hematology Analyzer.

110 Haemoglobin genotypes (AA, AS, SS \& SC) were determined by alkaline electrophoresis at pH of

112 G6PD status was determined quantitatively (RANDOX, UK). Respondents were classified as: 113 G6PD Normal if G6PD enzyme activity was $\geq 4000 \mathrm{mU} / \mathrm{gHb}(\geq 4.00 \mathrm{U} / \mathrm{gHb})$, G6PD Partial Defect 114 if G6PD enzyme activity was 1000 to $3999 \mathrm{mU} / \mathrm{gHb}(1.00-3.99 \mathrm{U} / \mathrm{gHb})$ and G6PD full defect if 
115 G6PD enzyme activity was $<1000 \mathrm{mU} / \mathrm{gHb}(<1.00 \mathrm{U} / \mathrm{gHb})$ according to protocol developed by

116 Owusu et al. [21].

117

\section{Outcomes}

119 Birth weight in grams (g) was measured within 24 hours after birth and LBW was diagnosed if a 120 neonate has a weight $<2500 \mathrm{~g} \mathrm{[1]}$. PE was diagnosed based on a systolic blood pressure $\geq 140 \mathrm{mmHg}$ 121 and/or diastolic blood pressure $(\geq 90 \mathrm{mmHg})$ on two separate occasions with proteinuria $(\geq 300 \mathrm{mg} / 24$

$122 \mathrm{~h}$ or ++ on a dipstick) after 20 weeks of gestation [22]. PPH was diagnosed based on a postpartum 123 blood loss of $1000 \mathrm{ml}$ or more in the immediate postpartum period [10].

124

\section{Data analysis}

126 Categorical variables were presented as frequencies and percentages and significance of association 127 was assessed using Chi-square or Fisher's exact test where applicable. Multivariate logistic 128 regression analysis was used to evaluate the risk factors of PPH, LBW and PE. Statistical analysis was performed using Stata version 14.2 and a p-value $<0.05$ was considered statistically significant. 


\section{Results}

136 A total of 268 pregnant women with mean age of 29.1 (SD: 5.8) years old and gestational age at $1^{\text {st }}$ 137 visit 27.2 (12.7) weeks were included. Majority of the women resided in urban communities 138 (59.7\%), were married (81.3\%), employed (68.7\%), multiparous (39.6\%) and began antenatal care 139 in third trimester (57.5\%). Most of the women were of the AA genotype (80.6\%) and O positive 140 blood group (67.9\%) (Table 1).

142 Table 1: Baseline characteristics of study population

\begin{tabular}{lcc}
\hline Variable & Mean \pm SD & Min-Max \\
\hline Maternal age (years) & $29.1 \pm 5.8$ & $14-41$ \\
Gestational age at first visit (weeks) & $27.2 \pm 12.6$ & $5-42$ \\
& $\mathbf{n}$ & $\%$ \\
Residency & 108 & 40.3 \\
Rural & 160 & 59.7 \\
Urban & & \\
Marital status & 218 & 81.3 \\
Married & 50 & 18.7 \\
Single & & \\
Occupation & 184 & 68.7 \\
Employed & 84 & 31.3 \\
Unemployed & & \\
Gestational age at 1st visit & 50 & 18.7 \\
1st Trimester & 64 & 23.9 \\
2nd Trimester & 154 & 57.5 \\
3rd Trimester & & 46.3 \\
Baby sex & 124 & \\
Female &
\end{tabular}


Male

\section{Parity at 1st visit}

Nulliparity $\quad 86$

32.1

Uniparity

76

28.4

Multiparity

106

39.6

\section{Mode of delivery}

Caesarian section $\quad 122$

45.5

Vaginal delivery

54.5

\section{Blood group}

A positive

26

9.7

$\mathrm{AB}$ positive

12

4.5

$B$ negative

4

1.5

B positive

36

13.4

$\mathrm{O}$ negative

8

3

O positive

182

67.9

\section{Sickling}

Negative

216

80.6

Positive

52

19.4

Hb genotype

A

216

80.6

AS

42

15.7

$\mathrm{S}$

10

3.7

1st Trimester Hb

$<11 \mathrm{~g} / \mathrm{dl}$

135

50.4

$>11 \mathrm{~g} / \mathrm{dl}$

133

49.6

\section{G6PD status}

full defect

14

5.2

partial defect

28

10.5

non defect

226

84.3

Hb: haemoglobin; G6PD: glucose-6-phosphate dehydrogenase. 


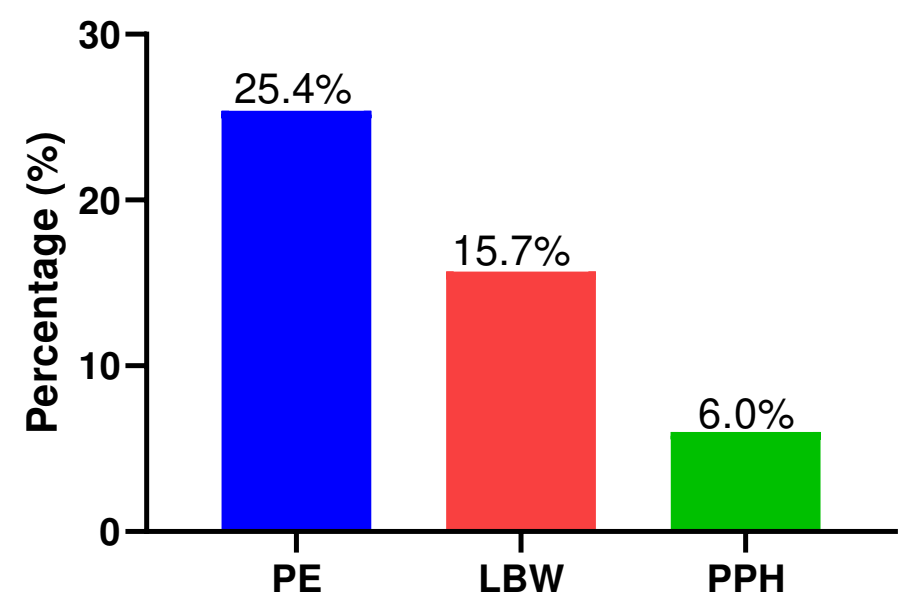

147

148

149

Figure 1: Prevalence of PE, LBW and PPH.

150 The prevalence of PE, LBW and PPH were 25.4\% (68/268), 15.7\% (42/268) and 6.0\% (16/268), 151 respectively (Figure 1).

152

153

Crude and adjusted odds ratio for factors potentially associated with PE

154 Younger aged pregnant women $(\mathrm{COR}=8.28,95 \% \mathrm{CI}(2.43-28.19), \mathrm{p}=0.001)$ and women who were 155 in their $3^{\text {rd }}$ trimester at $1^{\text {st }}$ ANC visit $(\mathrm{COR}=18.0,95 \%$ CI $(2.32-139.92), \mathrm{p}=0.000)$ presented with 156 increased odds of PE whereas living in the urban areas $(\mathrm{COR}=0.26,95 \% \mathrm{CI}(0.14-0.46), \mathrm{p}=0.000)$, 157 sickling positivity $(\mathrm{COR}=0.09,95 \% \mathrm{CI}(0.02-0.38), \mathrm{p}=0.001), \mathrm{Hb}$ genotype of $\mathrm{AS}(\mathrm{COR}=0.11$, $15895 \% \mathrm{CI}(0.03-0.48), \mathrm{p}=0.003)$, being unmarried $(\mathrm{COR}=0.34,95 \% \mathrm{CI}(0.14-0.85), \mathrm{p}=0.020)$, having 159 multiple children $(\mathrm{COR}=0.49,95 \% \mathrm{CI}(0.26-0.93), \mathrm{p}=0.030)$ and vaginal delivery $(\mathrm{COR}=0.49,95 \%$ 160 CI (0.28-0.85), $\mathrm{p}=0.012)$ were associated with lower odds of PE. Upon controlling for potential 
161 confounders in multivariate logistic regression, delayed $1^{\text {st }} \mathrm{ANC}$ visit (AOR=16.82, 95\% CI (3.61-

$16278.5), \mathrm{p}=0.000)$, younger maternal age $(\mathrm{AOR}=15.19,95 \% \mathrm{CI}(1.85-124.56), \mathrm{p}=0.011)$ and vaginal

163 delivery $(\mathrm{AOR}=0.32,95 \% \mathrm{CI}(0.15-0.71), \mathrm{p}=0.015)$ remained independently associated with $\mathrm{PE}$

164 (Table 2).

165

166 Table 2: Crude and adjusted odds ratio for factors potentially associated with PE

\begin{tabular}{|c|c|c|c|c|c|c|}
\hline Variable & $\begin{array}{c}\text { PE } \\
\text { absent }=100\end{array}$ & $\begin{array}{c}\mathrm{PE} \\
\text { present }=34\end{array}$ & $\operatorname{COR}(95 \% \mathrm{CI})$ & p-value & $\operatorname{AOR}(95 \% \mathrm{CI})$ & p-value \\
\hline \multicolumn{7}{|l|}{ Maternal age } \\
\hline $20-30$ & $120(76.81)$ & $16(23.19)$ & 1 & \multicolumn{3}{|c|}{1} \\
\hline$<20$ & $2(28.57)$ & $5(71.43)$ & $8.28(2.43-28.19)$ & 0.001 & $15.19(1.85-124.56)$ & 0.011 \\
\hline$>30$ & 45(77.59) & $13(22.41)$ & $0.96(0.53-1.72)$ & 0.884 & $0.98(0.46-2.05)$ & 0.947 \\
\hline \multicolumn{7}{|l|}{ Residency } \\
\hline Rural & $64(59.26)$ & $44(40.74)$ & 1 & & & \\
\hline Urban & $136(85.0)$ & $24(15.0)$ & $0.26(0.14-0.46)$ & 0.000 & $0.57(0.27-1.17)$ & 0.123 \\
\hline \multicolumn{7}{|l|}{ Marital status } \\
\hline Married & $156(71.56)$ & $62(28.44)$ & 1 & & & \\
\hline Single & $44(88.0)$ & $6(12.0)$ & $0.34(0.14-0.85)$ & 0.020 & $0.24(0.05-1.22)$ & 0.085 \\
\hline \multicolumn{7}{|l|}{ Occupation } \\
\hline Employed & $138(75.0)$ & $46(25.0)$ & 1 & & & \\
\hline Unemployed & $62(73.81)$ & $22(26.19)$ & $1.06(0.59-1.92)$ & 0.835 & & \\
\hline \multicolumn{7}{|c|}{$\begin{array}{l}\text { Gestational age at } 1 \text { st } \\
\text { visit }\end{array}$} \\
\hline 1st Trimester & $48(96.0)$ & $2(4)$ & 1 & & 1 & \\
\hline 2nd Trimester & $64(100.0)$ & $0(0.0)$ & - & & - & \\
\hline 3rd Trimester & $88(57.14)$ & $66(42.86)$ & $18(2.32-139.92)$ & 0.000 & $16.82(3.61-78.50)$ & 0.000 \\
\hline \multicolumn{7}{|l|}{ Baby sex } \\
\hline Female & $94(75.81)$ & $30(24.19)$ & 1 & & & \\
\hline Male & $106(73.61)$ & $38(26.39)$ & $1.12(0.65-1.95)$ & 0.681 & & \\
\hline \multicolumn{7}{|l|}{ Parity } \\
\hline Nulliparity & $56(65.12)$ & $30(34.88)$ & 1 & & 1 & \\
\hline Uniparity & $30(78.95)$ & $16(21.05)$ & $0.50(0.25-1.01)$ & 0.053 & $0.51(0.19-1.31)$ & 0.160 \\
\hline Multiparity & $84(79.25)$ & $22(20.75)$ & $0.49(0.26-0.93)$ & 0.030 & $0.41(0.17-1.00)$ & 0.051 \\
\hline \multicolumn{7}{|l|}{ Mode of delivery } \\
\hline vaginal delivery & $118(80.82)$ & $28(80.82)$ & $0.49(0.28-0.85)$ & 0.012 & $0.32(0.15-0.71)$ & 0.005 \\
\hline \multicolumn{7}{|l|}{ Hb genotype } \\
\hline A & $150(69.44)$ & $66(30.56)$ & 1 & & 1 & \\
\hline
\end{tabular}




\begin{tabular}{|c|c|c|c|c|c|c|}
\hline AS & $40(95.24)$ & $2(4.76)$ & $0.11(0.03-0.48)$ & 0.003 & 1 & \\
\hline S & 10(100) & 0 & - & & - & \\
\hline \multicolumn{7}{|l|}{ Sickling } \\
\hline Negative & $150(69.44)$ & $66(30.56)$ & 1 & & & \\
\hline Positive & $50(96.15)$ & $2(3.85)$ & $0.09(0.02-0.38)$ & 0.001 & $0.41(0.08-2.05)$ & 0.276 \\
\hline \multicolumn{7}{|c|}{ 1st Trimester Hb } \\
\hline$<11 \mathrm{~g} / \mathrm{dl}$ & $71(73.20)$ & $26(26.80)$ & 1 & & & \\
\hline$>11 \mathrm{~g} / \mathrm{dl}$ & $129(75.44)$ & $42(24.56)$ & $0.89(0.50-1.57)$ & 0.685 & & \\
\hline \multicolumn{7}{|l|}{ G6PD status } \\
\hline Non defect & $160(70.80)$ & $66(29.20)$ & 1 & & & \\
\hline Full defect & $12(85.71)$ & 2(14.29) & $0.40(0.09-1.86)$ & 0.244 & & \\
\hline Partial defect & $28(100)$ & 0 & - & - & & \\
\hline
\end{tabular}

167 Hb: haemoglobin; G6PD: glucose-6-phosphate dehydrogenase; PE: preeclampsia.

168

169 Crude and adjusted odds ratio of factors associated with LBW

170 Living in an urban area $(\mathrm{COR}=0.35,95 \% \mathrm{CI}(0.18-0.69), \mathrm{p}=0.002)$ and vaginal delivery $(\mathrm{COR}=$

$1710.36,95 \% \mathrm{CI}(0.18-0.71), \mathrm{p}=0.004)$ were associated with lower odds of $\mathrm{LBW}$. Delayed $1^{\text {st }} \mathrm{ANC}$ visit

172 was associated with higher odds of LBW (COR=3.26, 95\% CI (1.10-9.69), $\mathrm{p}=0.034)$. However, upon

173 controlling for confounders in the multivariate model, delayed $1^{\text {st }} \mathrm{ANC}$ visit $(\mathrm{AOR}=3.26,95 \% \mathrm{CI}$

174 (1.05-10.10), $\mathrm{p}=0.041)$ and vaginal delivery $(\mathrm{AOR}=0.36,95 \% \mathrm{CI}(0.17-0.74), \mathrm{p}=0.006)$ were

175 independently associated with LBW (Table 3).

176

177 Table 3: Crude and adjusted odds ratio of factors associated with LBW

\begin{tabular}{lclcccc}
\hline Variable & NBW=113 & LBW=21 & COR(95\%CI) & $\begin{array}{c}\text { p- } \\
\text { value }\end{array}$ & AOR(95\%CI) & $\begin{array}{l}\text { p- } \\
\text { value }\end{array}$ \\
\hline Maternal age & & & & & & \\
$20-30$ & $120(86.96)$ & $18(13.04)$ & 1 & & & \\
$<20$ & $10(71.43)$ & $4(28.57)$ & $2.67(0.76-9.41)$ & 0.127 & & \\
$>30$ & $96(82.76)$ & $20(17.24)$ & $1.39(0.70-2.77)$ & 0.351 & & \\
Residency & & & & & & \\
Rural & $82(75.93)$ & $26(24.07)$ & 1 & & 1 & \\
Urban & $144(90.0)$ & $16(10.0)$ & $0.35(0.18-0.69)$ & $\mathbf{0 . 0 0 2}$ & $0.53(0.26-1.09)$ & 0.083
\end{tabular}




\section{Marital status}

Married

$180(82.57) \quad 38(17.43)$

Single

46(92.0) 4(8.0)

$0.41(0.14-1.21)$

0.107

Occupation

Employed

158(85.87) 26(14.13)

1

Unemployed

68(80.95) 16(19.05)

$1.43(0.72-2.84) \quad 0.306$

Gestational age at 1st

\section{Visit}

1st Trimester

$46(92.0) \quad 4(8.0)$

1

60(93.75) 4(6.25)

0.77(0.10-5.86)

1

2nd Trimester

120(77.92) 34(22.08)

3.26(1.10-9.69)

$0.717 \quad 0.9(0.21-3.88)$

0.887

3rd Trimester

$\mathbf{0 . 0 3 4} 3.26(1.05-10.10)$

0.041

\section{Baby sex}

Female

100(80.65) 24(19.35)

126(87.50) 18(12.50)

1

Male

Parity

Nulliparity

68(79.07) 18(20.93)

68(89.47) 8(10.53)

$0.6(0.31-1.56)$

0.126

Uniparity

Multiparity

$90(84.91) \quad 16(15.09)$

1

Mode of delivery

caesarian section

vaginal delivery

94(77.05) 28(22.95)

0.44(0.18-1.09) $\quad 0.077$

$0.67(0.32-1.41) \quad 0.294$

\section{Hb-genotype}

A

AS

S

\section{Sickling}

Negative

Positive

1st Trimester $\mathbf{H b}$

$<11 \mathrm{~g} / \mathrm{dl}$

$>11 \mathrm{~g} / \mathrm{dl}$

\section{G6PD status}

Non defect

Full defect

Partial defect
132(90.41) 14(9.59)

$0.36(0.18-0.71)$

178(82.41) 38(17.59)

40(95.24) 2(4.76)

8(80.0) 2(20.0)

178(82.41) 38(17.59)

48(92.31) 4(7.69)

$0.39(0.13-1.45) \quad 0.087$

50(87.63) 4(12.37)

45(82.46) 6(17.54)

$0.23(0.05-1.01) \quad 0.052$

$1.17(0.24-5.73) \quad 0.846$

$0.004 \quad 0.36(0.17-0.74)$

0.006

188(83.19) 38(16.81)

12(85.71) 2(14.29)

$0.82(0.18-3.83) \quad 0.806$

52(92.86) 4(7.14)

0.38(0.09-1.67) $\quad 0.201$

178

G6PD: glucose-

179

low birth weight.

180

181

182 
184 Advanced maternal age $(\mathrm{COR}=3.87,95 \% \mathrm{CI}(1.21-12.33), \mathrm{p}=0.022)$ and male gender $(\mathrm{COR}=6.57$,

$18595 \%$ CI (1.46-29.5), $\mathrm{p}=0.014)$ were associated with higher odds of PPH whereas delayed $1^{\text {st }}$ ANC

186 visit $(\mathrm{COR}=0.14,95 \% \mathrm{CI}(0.04-0.49), \mathrm{p}=0.002)$ was associated with a reduced odds of PPH. Women

187 who were in their $3^{\text {rd }}$ trimester during their $1^{\text {st }}$ ANC visit $(\mathrm{AOR}=0.12,95 \% \mathrm{CI}(0.03-0.47), \mathrm{p}=0.002)$,

188 the aged women $(\mathrm{AOR}=3.96,95 \% \mathrm{CI}(1.17-13.35), \mathrm{p}=0.027)$ and neonates of male gender $189(\mathrm{AOR}=7.75,95 \%$ CI (1.60-37.51), p=0.011) were independently associated with PPH (Table 4).

190

191 Table 4: Crude odds ratio of factors associated with PPH

\begin{tabular}{|c|c|c|c|c|c|c|}
\hline Variable & $\begin{array}{c}\text { PPH } \\
\text { absent=126 }\end{array}$ & $\begin{array}{c}\text { PPH } \\
\text { present }=8\end{array}$ & $\operatorname{COR}(95 \% \mathrm{CI})$ & $\begin{array}{c}\text { p- } \\
\text { value }\end{array}$ & $\operatorname{AOR}(95 \% \mathrm{CI})$ & $\begin{array}{c}\text { p- } \\
\text { value }\end{array}$ \\
\hline \multicolumn{7}{|l|}{ Maternal age } \\
\hline $20-30$ & $134(97.1)$ & $4(2.9)$ & 1 & & & \\
\hline$<20$ & $14(100.0)$ & $0(0.0)$ & - & & & \\
\hline$>30$ & 104(89.66) & $12(10.34)$ & $3.87(1.21-12.33)$ & 0.022 & $3.96(1.17-13.35)$ & 0.027 \\
\hline \multicolumn{7}{|l|}{ Residency } \\
\hline Rural & 104(96.3) & $4(3.7)$ & 1 & & & \\
\hline Urban & $148(92.5)$ & $12(7.5)$ & $2.11(0.66-6.72)$ & 0.207 & & \\
\hline \multicolumn{7}{|l|}{ Marital status } \\
\hline Married & 204(93.58) & $14(6.42)$ & 1 & & & \\
\hline Single & 48(96.0) & $2(4.0)$ & $0.61(0.13-2.76)$ & 0.518 & & \\
\hline \multicolumn{7}{|l|}{ Occupation } \\
\hline Employed & $170(92.39)$ & $14(7.61)$ & 1 & & & \\
\hline $\begin{array}{l}\text { Unemployed } \\
\text { Gestational age at } \\
\text { 1st Visit }\end{array}$ & $82(97.62)$ & $2(2.38)$ & $0.30(0.07-1.33)$ & 0.113 & & \\
\hline 1st Trimester & $42(84)$ & $8(16)$ & 1 & & 1 & \\
\hline 2nd Trimester & $60(93.75)$ & $4(6.25)$ & $0.35(0.10-1.24)$ & 0.103 & $0.28(0.07-1.07)$ & 0.064 \\
\hline 3rd Trimester & $150(97.4)$ & $4(2.6)$ & $0.14(0.04-0.49)$ & 0.002 & $0.12(0.03-0.47)$ & 0.002 \\
\hline \multicolumn{7}{|l|}{ Baby sex } \\
\hline Female & $122(98.39)$ & $2(1.61)$ & 1 & & 1 & \\
\hline $\begin{array}{l}\text { Male } \\
\text { Parity }\end{array}$ & $130(90.28)$ & $14(9.72)$ & $6.57(1.46-29.50)$ & 0.014 & $7.75(1.60-37.51)$ & 0.011 \\
\hline
\end{tabular}




\begin{tabular}{lcccc}
\hline Nulliparity & $80(93.02)$ & $6(6.98)$ & 1 & \\
Uniparity & $70(92.11)$ & $6(7.89)$ & $1.14(0.35-3.71)$ & 0.824 \\
Multiparity & $102(96.23)$ & $4(5.97)$ & $0.52(0.14-1.92)$ & 0.328 \\
Mode of delivery & & & & \\
caesarian section & $116(95.08)$ & $6(4.92)$ & 1 & \\
vaginal delivery & $136(93.15)$ & $10(6.85)$ & $1.42(0.50-4.03)$ & 0.508 \\
Hb genotype & & & & \\
A & $202(93.52)$ & $14(6.48)$ & 1 & - \\
AS & $42(100)$ & $0(0.0)$ & - & - \\
S & $8(80)$ & $2(20)$ & $3.61(0.70-18.62)$ & 0.126 \\
Sickling & & & \\
Negative & $202(93.52)$ & $14(6.48)$ & 1 & \\
Positive & $50(96.15)$ & $2(3.85)$ & $0.58(0.13-2.62)$ & 0.477 \\
1st Trimester Hb & & & & \\
$<11$ g/dl & $89(91.75)$ & $8(8.25)$ & 1 & \\
$>11 \mathrm{~g} / \mathrm{dl}$ & $163(95.32)$ & $8(4.68)$ & $0.55(0.20-1.50)$ & 0.242 \\
G6PD status & & & & \\
Non defect & $214(94.69)$ & $12(5.31)$ & 1 & - \\
Full defect & $14(100)$ & 0 & - & - \\
Partial defect & $24(85.71)$ & $4(14.29)$ & $2.97(0.89-9.94)$ & 0.077 \\
\hline
\end{tabular}

192 PPH: postpartum hemorrhage; Hb: haemoglobin; G6PD: glucose-6-phosphate dehydrogenase.

193

194 Discussion

195 The prevalence of PE in our study is $25.4 \%$. In 2006, a study in Accra, Ghana, by Obed and Patience 196 found a PE prevalence of 7.03\% [16]. In 2013, Adu-Bonsaffoh et al. also found a 7.9\% prevalence 197 of PE in Accra [23]. The higher prevalence in this study compared to previous studies in Southern

198 Ghana could be due to the small sample size and differences in socioeconomic and socio199 demographic factors such as employment, level of education, younger maternal age etc. Formal 200 education and employment status have been demonstrated to reduce the risk of many conditions 201 including PE [24] . However, most of the women from the Northern part of Ghana have inadequate 202 formal education and are either unemployed or engage in small scale jobs such as basket weaving, 203 petty trading and subsistence farming. Indeed, the Ghana Poverty Mapping Report by the Ghana 
204 Statistical Service identifies the Northern regions of Ghana as the most deprived regions [25].

205 Additionally, young women are given out for marriage at a tender age in most parts of Northern

206 Ghana. These factors could account for the higher prevalence of PE in this study.

207 There was an 18-fold increased odds of PE among pregnant women who had their $1^{\text {st }}$ antenatal 208 booking in their $3^{\text {rd }}$ trimester of pregnancy. The delayed first ANC booking was independently 209 associated with increased risk of PE. Timely ANC booking facilitates early identification of signs 210 related to various conditions during pregnancy. This allows for early intervention and improvement 211 of health outcomes for both the mother and baby [24]. Indeed, You et al. in a study in the US, 212 proposed that a substantial number of the serious complications of PE could be prevented through 213 identification of symptoms through early reporting by patients [26]. It is therefore not surprising that delayed first ANC visit was associated with PE. On the other hand, urban settlement was associated with reduced odds of PE. Affirmatively, a study conducted in India by Sahu et al. [4] found rural residents to have increased risk of PE compared to urban residents. The reduced odds of PE among urban residents could be attributed to the availability and access to quality health care in the urban centers compared to the rural setting.

Younger-aged pregnant women were independently associated with increased odds of PE. This finding concurs with the finding of Endeshaw et al. in Ethiopia [27]. PE is a multisystem disorder of an unknown cause hence younger pregnant women who do not have the requisite physiological make up and resources for pregnancy and parturition suffer adverse consequences. Additionally, multiparity conferred protection against PE in our cohort as it reduced the odds of PE by $51 \%$. This protection may be due to immunological intolerance among primiparous women until the first successful pregnancy induces adaptive changes leading to immunological tolerance in successive 226 pregnancies. 
227 The AS haemoglobin genotype was also found to be associated with reduced odds of PE. This

228 finding is similar to the findings of Stamilio et al. [28] in the United States. The findings in this 229 study, however, differs from those of Larrabee \& Monga [29], who found AS genotype to be 230 significantly associated with an increased odds of PE. The varying association between AS genotype 231 and PE may be due to differences in sample size used and sensitivity of the screening tests 232 performed.

233 Our study also reports a significant reduction in the risk of PE in single mothers compared to the 234 married counterparts. Findings of studies done in Ghana by Addai-Mensah et al. 2018 and Roman et al. 2019 [30, 31] differs from ours. They found that married pregnant women were more likely to go for ANC visits than single women possibly due to support from their spouses in compelling them to follow the required guidelines for safe pregnancy and delivery. Additionally, husbands played an economic role in the frequency of a pregnant women's ANC visits with some men taking up the responsibility of maintaining the wellbeing of their pregnant wives by ensuring that they attend ANC clinics.

241 We found a LBW prevalence of $15.7 \%$ in this study. This finding is higher compared to a study by 242 Adam et al. in the Brong Ahafo region who reported a LBW prevalence of $11 \%$ [37]. Our finding is 243 also higher than the LBW prevalence of 13.7\% reported by Agorinya et al. based on data from 2009 to 2011 in the Northern part of Ghana [38]. The LBW prevalence recorded in this study is also slightly higher than the national prevalence of $10.7 \%$ [39]. Overall, although the prevalence of LBW in Northern Ghana is high in this study compared to previous studies in the region, the degree of increase is only marginal.

LBW has been associated with several factors including nutritional factors, younger and advanced maternal age, parity, limited birth spacing, low pre-pregnancy BMI and parasitic infections. In this 
study, we found urban residence to be associated with a reduction in the odds of producing babies with LBW. This finding agrees with a study by Mahumud et al. in Bangladesh who found rural settlement to be associated with an increased odds of LBW [40]. Women from urban parts of the Northern sector of Ghana have access to quality health care, potable water, majority are educated and employed with requite knowledge of nutrition and balanced diet. They also readily adhere to antenatal regimen [26]. These advantages of the urban residents over the rural residents may account for the reduced the likelihood of LBW among women from the urban parts of the study area. As anticipated, vaginal delivery was also associated with lower odds of LBW. Majority of caesarian section deliveries are as result of foeto-maternal complications hence it is not surprising that vaginal delivery presented with reduced odds of producing babies with LBW. This finding agrees with that of a study in China by Chen et al. who reported caesarian delivery to be associated with increased odds of LBW [41]. We found delayed $1^{\text {st }}$ ANC visit as an independent risk factor for LBW as reported elsewhere $[42,43]$.

The prevalence of PPH in this study was $6 \%$ which is equal in magnitude to the global incidence of $6 \%$ [44]. The highest burden of PPH (10.5\%) occurs in low income countries like Sub-Saharan Africa and Asia [45]. Advanced maternal age was independently associated with an increased odds of PPH similar to studies done elsewhere who also found several risk factors for PPH; past history of PPH, multigravida, macrosomia, primigravida, grand multi-parity, advanced maternal age, younger pregnant women, preterm births, labour induction, cesarean birth [46-48]. Surprisingly, delayed $1^{\text {st }}$ ANC visit independently reduced the risk of PPH in our study contrary to the findings of Haftu et al. in Ethiopia who found it to be associated with high incidence of PPH [49]. The male gender was independently associated with increased odds of PPH. This suggests that male neonates may have certain physiological features which may trigger obstetric hemorrhage in the mother hence further investigations should be done in this area. 


\section{Strength and limitation of the study}

275 This study included singleton pregnancies, allowing for the control of the confounding effect of twin 276 gestations. Recent studies on the prevalence and risk factors of PE, LBW and PPH in Northern

277 Ghana is limited; thus, this study provides current data on these conditions. It further serves as a 278 baseline data on foeto-maternal complications in Ghana upon which further studies could be

279 referenced and conclusions drawn for proper management of the conditions.

280 This study is however limited by the cross-sectional study design and limited sample size. As a 281 result, the findings of this study cannot be generalized to the general population. We recommend large longitudinal studies to better understand the changes in perinatal outcome indicators and factors contributing to PE, LBW and PPH in Ghana.

\section{Conclusion}

The study identified delayed ANC visit as an independent risk factor for PE, LBW and PPH in Northern Ghana. Vaginal delivery independently reduced the odds of PE whereas younger maternal age increased the odds of PE. Additionally, the male gender was independently associated with increased odds of PPH whereas vaginal delivery was independently associated with reduced odds of LBW. We recommend that public health education for pregnant women that highlights the importance of early ANC visit be enhanced. This will facilitate early identification and intervention for women with risk of foeto-maternal complications. Younger women should be educated on the dangers of early marriages with its attendant foeto-maternal complications of pregnancy such as PE,

LBW, neonatal respiratory distress, maternal death, NICU admissions and neonatal death. 


\section{List of abbreviations}

296 LBW: Low Birth Weight; PPH: Postpartum Hemorrhage; PE: Preeclampsia; ANC: Antenatal Care;

297 G6PD: Glucose-6-Phosphate Dehydrogenase; CI: Confidence Interval; Hb: Haemoglobin; WHO:

298 World Health Organisation; BMI: Body Mass Index; NBW: Normal Birth Weight; NICU: Neonatal

299 Intensive Care Unit; COR: Crude Odds Ratio; AOR: Adjusted Odds Ratio; SD: Standard Deviation.

300

301 Declarations

302 Funding

303 This research did not receive any specific grant from funding agencies in the public, commercial, or 304 not-for-profit sectors.

305 Consent for publication

306 Not applicable

307 Availability of data and materials

308 The datasets used and analysed during the current study are available from the corresponding

309 author on reasonable request.

310

311 Conflict of Interest

312 The authors declare that they have no competing interests. 


\section{Ethics approval and consent to participate}

315 Ethical approval for this study was obtained from the institutional review board of the Navrongo

316 Health Research Centre of the Ghana Health Service. Written informed consent was obtained from

317 all participants who opted to participate after the aims and objectives of the study had been explained

318 to them. Participation was voluntary, and respondents were assured that the information obtained

319 was strictly for research and academic purposes only and were guaranteed the liberty to opt out from

320 the study at their own convenience.

321

322 Author contributions

323 BA, BG, RKOE and EWO conceived and designed the study. BA drafted the manuscript. BA, EWO 324 and DA analyzed the data. BAM, EMD, SAS, GH, PAJ, SC and WO contributed with valuable 325 references. All authors read and revised the manuscript and gave final approval of the manuscript.

327 Acknowledgments

328 The authors express their gratitude to all staff and patients of the Bolgatanga Regional Hospital who 329 actively participated in this study. 


\section{References}

333 1. Weise A. WHA Global Nutrition Targets 2025: Low Birth Weight Policy Brief. WHO Publ. 334 2012;:1-7. doi:WHO/NMH/NHD/14.3.

335 2. McIntire DD, Bloom SL, Casey BM, Leveno KJ. Birth Weight in Relation to Morbidity and

336 Mortality among Newborn Infants. N Engl J Med. 1999;340:1234-8.

337 doi:10.1056/nejm199904223401603.

338 3. Kinney M V., Kerber KJ, Black RE, Cohen B, Nkrumah F, Coovadia H, et al. Sub-Saharan

339 Africa's Mothers, Newborns, and Children: Where and Why Do They Die? PLoS Med.

$340 \quad$ 2010;7:e1000294. doi:10.1371/journal.pmed.1000294.

341 4. Sahu AS, Mitra S, Mandal N. A study on safe motherhood and child survival in coming days

342 and to reduce infant mortality: Promote maternal and child health care. $\sim 14 \sim$ Int J Physiol.

343 2016;1:14-24. www.journalofsports.com. Accessed 3 Mar 2020.

344 5. de Onis M. Child Growth and Development. In: Nutrition and Health in a Developing World.

345 Springer International Publishing; 2017. p. 119-41.

346 6. McCormick MC. The Contribution of Low Birth Weight to Infant Mortality and Childhood

347 Morbidity. New England Journal of Medicine. 1985;312:82-90.

348 7. Agorinya IA, Kanmiki EW, Nonterah EA, Tediosi F, Akazili J, Welaga P, et al. Socio-

349 demographic determinants of low birth weight: Evidence from the Kassena-Nankana districts of

350 the Upper East Region of Ghana. PLoS One. 2018;13.

351 8. Schimmel MS, Bromiker R, Hammerman C, Chertman L, Ioscovich A, Granovsky-Grisaru S, et

352 al. The effects of maternal age and parity on maternal and neonatal outcome. Arch Gynecol Obstet. 
354 9. Abubakari A, Kynast-Wolf G, Jahn A. Maternal determinants of birth weight in Northern 355 Ghana. PLoS One. 2015;10.

356 10. American College of Obstetricians and Gynecologists. ACOG Practice Bulletin: Clinical

357 Management Guidelines for Obstetrician-Gynecologists Number 76, October 2006: postpartum

358 hemorrhage. Obstet Gynecol. 2006;108:1039-47.

359 http://www1.health.nsw.gov.au/pds/ActivePDSDocuments/. Accessed 3 Mar 2020.

360 11. Nagenthiran S, Ghosh M, Srinivasan M. Anaemia - a prevalent risk factor for post-partum

361 haemorrhage. Eur J Obstet Gynecol Reprod Biol. 2016;206:e83. doi:10.1016/j.ejogrb.2016.07.225.

362 12. Valdes V, Adongo PB, Nwameme AU, Tabong PTN, Fernandes M. Risk factors for self363 reported postpartum hemorrhage in Ga East, Ghana. Int J Gynecol Obstet. 2018;142:201-6. Journal of Nursing and Midwifery The prevalence, management and outcome of primary postpartum haemorrhage in selected health care facilities in Nigeria. 2013;5:28-34. doi:10.5897/IJNM12.011.

14. Abalos E, Cuesta C, Grosso AL, Chou D, Say L. Global and regional estimates of preeclampsia and eclampsia: A systematic review. European Journal of Obstetrics and Gynecology and Reproductive Biology. 2013;170:1-7. doi:10.1016/j.ejogrb.2013.05.005. from Dilla region of Ethiopia. BMC Res Notes. 2015;8:816. doi:10.1186/s13104-015-1821-5. 
374 Ghana Med J. 2006;40:8-13. http://www.ncbi.nlm.nih.gov/pubmed/17299557. Accessed 4 Mar 3752020.

376 17. Dassah ET, Kusi-Mensah E, Morhe ESK, Odoi AT. Maternal and perinatal outcomes among

377 women with hypertensive disorders in pregnancy in Kumasi, Ghana. PLoS One.

$378 \quad 2019 ; 14: \mathrm{e} 0223478$. doi:10.1371/journal.pone.0223478.

379 18. Iki M. Primary, secondary and tertiary prevention of osteoporosis. Clinical calcium. $380 \quad 2006 ; 16: 18-23$. doi:CliCa060914381443.

381 19. Breslow L. Prevention and control of noncommunicable diseases. World Health Forum.

382 1982;3:429-31. doi:10.1093/med/9780199661756.003.0237.

383 20. Cheesbrough M, Cheesbrough M. Microbiological tests. In: District Laboratory Practice in 384 Tropical Countries. 2009. p. 1-266.

385 21. Owusu R, Asante KP, Mahama E, Awini E, Anyorigiya T, Dosoo D, et al. Glucose-6386 phosphate dehydrogenase deficiency and haemoglobin drop after sulphadoxine-pyrimethamine use 387 for intermittent preventive treatment of malaria during pregnancy in Ghana - A cohort study. PLoS 388 One. $2015 ; 10$.

22. Woelkers D, Barton J, von Dadelszen P, Sibai B. [71-OR]: the revised 2013 ACOG definitions 390 of hypertensive disorders of pregnancy significantly increase the diagnostic prevalence of 391 preeclampsia. Pregnancy Hypertens An Int J Women’s Cardiovasc Heal. 2015;5:38.

392 23. ADU-BONSAFFOH K, Y Ntumy M, A Obed S, D Seffah J. Prevalence of hypertensive 393 disorders in pregnancy at Korle-Bu Teaching Hospital in Ghana. J Gynecol NEONATAL Biol. $3942017 ; 3: 1-6$. 
395

396

397

398

399

400

401

402

403

404

405

406

407

408

409

410

411

412

413

414

415

24. Fondjo LA, Boamah VE, Fierti A, Gyesi D, Owiredu EW. Knowledge of preeclampsia and its associated factors among pregnant women: A possible link to reduce related adverse outcomes. BMC Pregnancy Childbirth. 2019;19.

25. Pereira AL dos S. No TitleÉ?_. 2015.

26. You WB, Wolf M, Bailey SC, Pandit AU, Waite KR, Sobel RM, et al. Factors Associated with Patient Understanding of Preeclampsia. Hypertens Pregnancy. 2012;31:341-9. doi:10.3109/10641955.2010.507851.

27. Endeshaw M, Ambaw F, Aragaw A, Ayalew A. Effect of Maternal Nutrition and Dietary Habits on Preeclampsia: A Case-Control Study. Int J Clin Med. 2014;05:1405-16.

28. Stamilio DM, Sehdev HM, Macones GA. Pregnant women with the sickle cell trait are not at increased risk for developing preeclampsia. Am J Perinatol. 2003;20:41-8.

29. Larrabee KD, Monga M. Women with sickle cell trait are at increased risk for preeclampsia. Am J Obstet Gynecol. 1997;177:425-8. doi:10.1016/S0002-9378(97)70209-6.

30. Roman E, Andrejko K, Wolf K, Henry M, Youll S, Florey L, et al. Determinants of uptake of intermittent preventive treatment during pregnancy: a review. Malar J. 2019;18:372. doi:10.1186/s12936-019-3004-7.

31. Addai-Mensah O, Annani-Akollor ME, Fondjo LA, Sarbeng K, Anto EO, Owiredu EW, et al. Regular antenatal attendance and education influence the uptake of intermittent preventive treatment of malaria in pregnancy: A cross-sectional study at the University Hospital, Kumasi, Ghana. J Trop Med. 2018;2018.

32. Mezey GC, Bewley S. Domestic violence and pregnancy. BJOG: An International Journal of 
416 Obstetrics and Gynaecology. 1997;104:528-31.

417 33. Gottlieb AS. Domestic violence: a clinical guide for women's healthcare providers. Obstet 418 Gynaecol. 2012;14:197-202.

419

420

421

422

423

424

425

426

427

428

429

430

431 demographic determinants of low birth weight: Evidence from the Kassena-Nankana districts of 432

433

434 435

34. Tavoli Z, Tavoli A, Amirpour R, Hosseini R, Montazeri A. Quality of life in women who were exposed to domestic violence during pregnancy. BMC Pregnancy Childbirth. 2016;16:19. doi:10.1186/s12884-016-0810-6.

35. Alhusen JL, Ray E, Sharps P, Bullock L. Intimate partner violence during pregnancy: Maternal and neonatal outcomes. J Women's Heal. 2015;24:100-6. doi:10.1089/jwh.2014.4872.

36. Abdollahi F, Abhari FR, Charati JY, Rouhani S. Impact of psychological violence on pregnancy outcomes in a prospective study. Iran J Psychiatry Behav Sci. 2014;8:22-7. www.ijpbs.mazums.ac.ir. Accessed 26 Oct 2020.

37. Adam Z, Ameme DK, Nortey P, Afari EA, Kenu E. Determinants of low birth weight in neonates born in three hospitals in Brong Ahafo region, Ghana, 2016- an unmatched case-control study. BMC Pregnancy Childbirth. 2019;19:174. doi:10.1186/s12884-019-2315-6.

38. Agorinya IA, Kanmiki EW, Nonterah EA, Tediosi F, Akazili J, Welaga P, et al. Sociothe Upper East Region of Ghana. PLoS One. 2018;13:e0206207. doi:10.1371/journal.pone.0206207.

39. Ghana - Multiple Indicator Cluster Survey 2011 - Overview. 2011. http://www2.statsghana.gov.gh/nada/index.php/catalog/52. Accessed 23 Jul 2020.

40. Mahumud RA, Sultana M, Sarker AR. Distribution and determinants of low birth weight in 
437 developing countries. J Prev Med Public Heal. 2017;50:18-28.

438 41. Chen Y, Wu L, Zhang W, Zou L, Li G, Fan L. Delivery modes and pregnancy outcomes of low 439 birth weight infants in China. J Perinatol. 2016;36:41-6.

440 42. Enkin M, Keirse M, Neilson J, Crowther C, Duley L. A guide to effective care in pregnancy 441 and childbirth. 1995. http://www.cwhn.ca/en/node/21208. Accessed 26 Oct 2020.

442 43. Ali N, Elbarazi I, Alabboud S, Al-Maskari F, Loney T, Ahmed LA. Antenatal Care Initiation 443 Among Pregnant Women in the United Arab Emirates: The Mutaba'ah Study. Front Public Heal. $444 \quad$ 2020;8:211. doi:10.3389/fpubh.2020.00211.

445 44. Carroli G, Cuesta C, Abalos E, Gulmezoglu AM. Epidemiology of postpartum haemorrhage: a 446 systematic review. Best Practice and Research: Clinical Obstetrics and Gynaecology. $447 \quad 2008 ; 22: 999-1012$.

448 45. AbouZahr C. Global burden of maternal death and disability. Br Med Bull. 2003;67:1-11. 449 doi:10.1093/bmb/ldg015.

450 46. Fukami T, Koga H, Goto M, Ando M, Matsuoka S, Tohyama A, et al. Incidence and risk 451 factors for postpartum hemorrhage among transvaginal deliveries at a tertiary perinatal medical 452 facility in Japan. PLoS One. 2019;14:e0208873. doi:10.1371/journal.pone.0208873.

453 47. Tort J, Rozenberg P, Traoré M, Fournier P, Dumont A. Factors associated with postpartum 454 hemorrhage maternal death in referral hospitals in Senegal and Mali: a cross-sectional 455 epidemiological survey. BMC Pregnancy Childbirth. 2015;15:235. doi:10.1186/s12884-015-0669$456 \mathrm{y}$.

457 48. Ononge S, Mirembe F, Wandabwa J, Campbell OMR. Incidence and risk factors for 
458 postpartum hemorrhage in Uganda. Reprod Health. 2016;13:38. doi:10.1186/s12978-016-0154-8.

459 49. Haftu A, Hagos H, Mehari M-A, G/her B. Pregnant women adherence level to antenatal care 460 visit and its effect on perinatal outcome among mothers in Tigray Public Health institutions, 2017:

461 cohort study. BMC Res Notes. 2018;11. doi:10.1186/s13104-018-3987-0. 


\section{Figures}

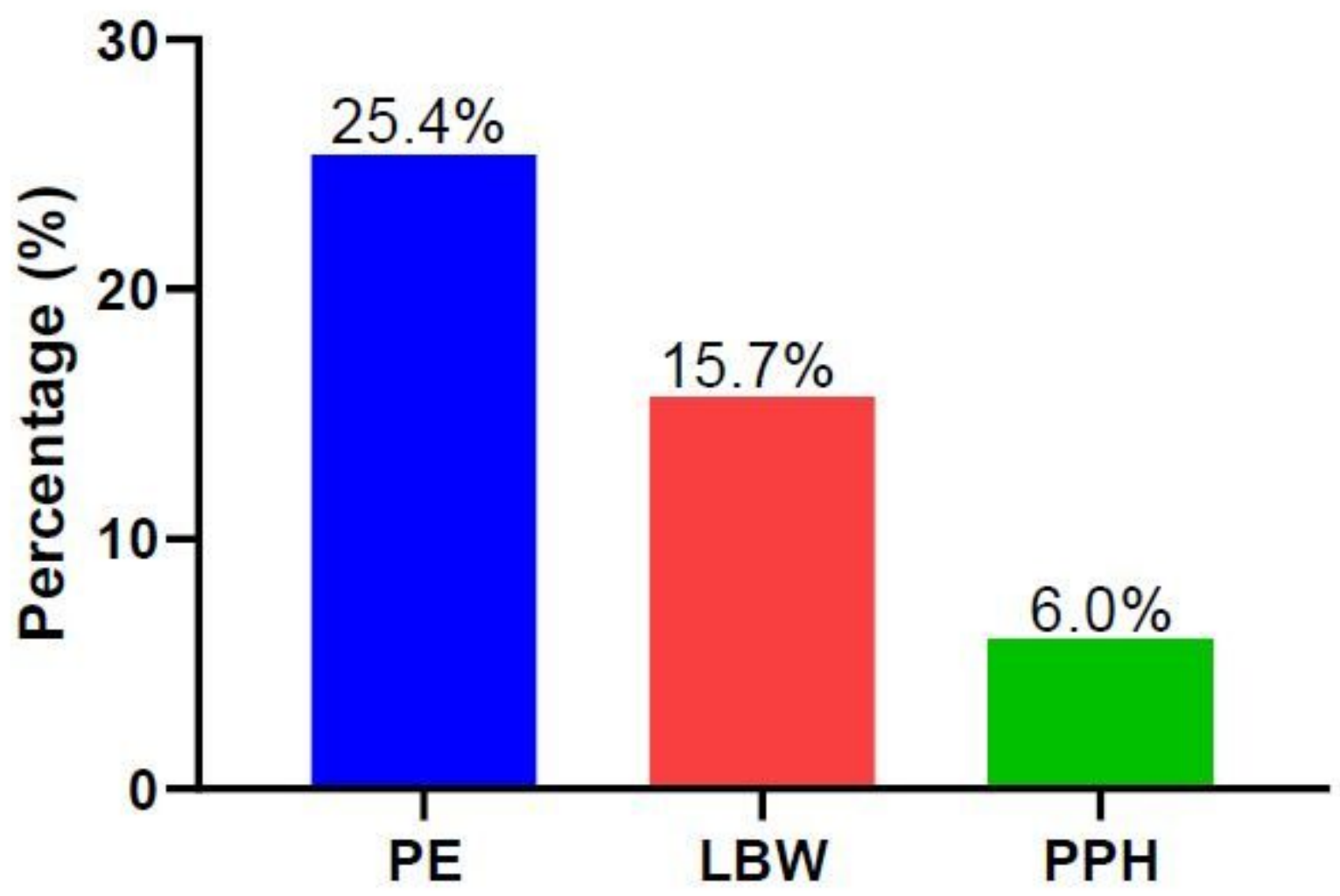

Figure 1

Prevalence of PE, LBW and PPH. The prevalence of PE, LBW and PPH were $25.4 \%(68 / 268), 15.7 \%$ $(42 / 268)$ and $6.0 \%(16 / 268)$, respectively (Figure 1$)$.

\section{Supplementary Files}

This is a list of supplementary files associated with this preprint. Click to download.

- QuestionnaireJournalPregnancyChildHealth.docx 